\title{
Enerji Tüketiminin Cari Açık Üzerindeki Etkisinin Panel Veri Yöntemleri ile Analizi: Karadeniz Ekonomik İşbirliği Örgütü'ne Dair Kanıtlar
}

\author{
Analysis of the Effect of Energy Consumption on Current Account Deficit \\ Using Panel Data: Evidence from the Organization of the Black Sea \\ Economic Cooperation
}

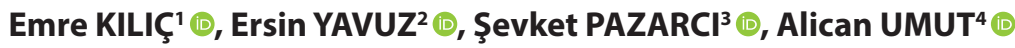

\section{öz}

Bu çalışmada Karadeniz Ekonomik İşbirliği Örgütü ülkeleri için cari açık ile enerji tüketimi arasındaki ilişki incelenmektedir. Bu bağlamda bağımsız değişken olarak toplam enerji tüketimi verileri kullanılmıştır. Karadeniz Ekonomik İşbirliği Örgütü ülkeleri için toplam enerji tüketimi verilerine 2014 yılına kadar erişilebilmesi nedeniyle örneklem dönemi olarak 19922014 dönemi belirlenmiştir. Ekonometrik analizde ilk olarak panele ilişkin homojenlik, yatay kesit bağımlılık ve durağanlık durumları incelenmiştir. Varsayım testleri doğrultusunda seriler arasındaki eşbütünleşme ilişkisinin belirlenebilmesi için yatay kesit bağımlılığını dikkate alan Westerlund (2007) panel eşbütünleşme testinden yararlanılmıştır. Analiz sonuçları cari açık ve toplam enerji tüketiminin eşbütünleşik olduğunu göstermektedir. Bu sonuç, Karadeniz Ekonomik İşbirliği Örgütü ülkelerinde cari açık ile enerji tüketiminin uzun dönemde birlikte hareket etme eğiliminde olduğunu göstermektedir. Daha sonra enerji tüketiminin cari açık üzerindeki etkisinin yönü ve boyutunun incelenebilmesi için Pedroni (2001) tarafından önerilen ortalama grup dinamik en küçük kareler tahmincisi kullanılarak uzun dönem katsayı tahmini gerçekleştirilmiştir. Katsayı tahmin sonuçları incelendiğinde Karadeniz Ekonomik İşbirliği Örgütü ülkelerinde enerji tüketiminin cari açığı negatif yönde etkilediği yani enerji tüketimindeki artışın cari açığı arttırıcı etki yapacağı sonucuna ulaşılmıştır. Bu sonuçlar Karadeniz Ekonomik İşbirliği Örgütü ülkelerinde oluşturulması gereken enerji politikalarında oldukça önem arz etmektedir. Bu bağlamda Karadeniz Ekonomik İşbirliği Örgütü ülkelerinde cari açığı azaltmak için enerji tüketiminin kontrol altına alınması ve/veya

\section{DOI: 10.26650/JEPR.945175}

'Nișantaşı Üniversitesi, İktisadi, İdari ve Sosya Bilimler Fakültesi, Sermaye Piyasaları ve Portföy Yönetimi Bölümü, İstanbul, Türkiye

${ }^{2}$ Pamukkale Üniversitesi, İktisadi ve İdari Bilimler Fakültesi, Maliye Bölümü, Denizli, Türkiye

${ }^{3}$ Nişantaşı Üniversitesi, İktisadi, İdari ve Sosyal Bilimler Fakültesi, Finans ve Bankacılık Bölümü, Istanbul, Türkiye

${ }^{4}$ Nişantaşı Üniversitesi, İktisadi, İdari ve Sosyal Bilimler Fakültesi, Ekonomi ve Finans Bölümü, İstanbul, Türkiye

ORCID: E.K. 0000-0003-2900-5123;

E.Y. 0000-0002-2543-3393;

S.P. 0000-0002-3675-909X;

A.U. 0000-0003-4184-3015

Sorumlu yazar/Corresponding author: Emre KILIÇ,

Nişantaşı Üniversitesi, İktisadi, İdari ve Sosyal Bilimler Fakültesi, Sermaye Piyasaları ve Portföy Yönetimi Bölümü, İstanbul, Türkiye

E-posta/E-mail: emre.kilic@nisantasi.edu.tr

Başvuru/Submitted: 30.05 .2021

Revizyon Talebi/Revision Requested: 28.06.2021 Son Revizyon/Last Revision Received: 02.07.202 Kabul/Accepted: 08.07.2021

Atıf/Citation: Kilic, E., Yavuz, E., Pazarci, S., Umut, A (2021). Enerji tüketiminin cari açık üzerindeki etkisinin panel veri yöntemleri ile analizi: Karadeniz Ekonomik İşbirliği Örgütü'ne dair kanıtlar. İktisat Politikası Araştırmaları Dergisi - Journal of Economic Policy Researches, 8(2), 277-291.

https://doi.org/10.26650/JEPR.945175 
yenilenebilir enerji kaynakları gibi enerjide dışa bağımlılık oranının azaltılmasını sağlayacak politik hamleler yapılması önerilmektedir.

Anahtar Kelimeler: Ekonometri, Panel veri, Cari açık, Enerji tüketimi, Karadeniz Ekonomik İşbirliği Örgütü Jel Sınıflaması: C23, F32, Q43

\begin{abstract}
This study examines the relationship between current account deficit and energy consumption among countries in the Organization of the Black Sea Economic Cooperation (BSEC), with total energy consumption data as an independent variable. Since data for BSEC countries are only available up to 2014, 1992-2014 is the sample period examined. Homogeneity, cross-section dependence, and stationarity conditions of the panel were examined in the econometric analysis. Westerlund (2007) panel cointegration test, which considers cross-sectional dependence, was used to determine the cointegration relationship between the series in line with the assumption tests. The analysis revealed the cointegration of current account deficit and total energy consumption, indicating that current account deficit and energy consumption tend to move together in the long run in BSEC countries. To examine the direction and size of the effect of energy consumption on current account deficit, a long-term coefficient estimation was performed using Pedroni (2001) proposed average group dynamic least squares estimator. Coefficient estimation results indicate that energy consumption in BSEC countries negatively affects current account deficit, indicating that increased energy consumption raises current account deficit. These results are essential to the development of energy policies in BSEC countries. In this context, it is recommended to establish policies to reduce current BSEC countries' account deficit by controlling energy consumption and/or reducing the rate of external energy dependency by further integrating renewable energy sources. This study extends existing research in terms of the sample group and the econometric method applied.
\end{abstract}

Keywords: Econometrics, Panel data, Current account deficit, Energy consumption, Black Sea economies

Jel Classification: C23, F32, Q43

\title{
EXTENDED ABSTRACT
}

In recent years, population growth, urbanization, and rising social welfare have led to increasing demand for energy. With technological development, social needs and production methods are continuously changing, and reliable energy resources are vital for all production methods, from the industrial revolution to the present. Because of the insufficiency of their energy reserves, some countries are dependent on energy-exporting countries. This circumstance may cause problems regarding current account deficit in energy importing countries. The high rate of current account deficit makes importing countries economies fragile. Many macroeconomic variables, particularly exchange rates, interest rates, inflation rates, and investment policies, are affected by current account deficit. Therefore, governments focus on the factors that cause current account deficit in relation to economic performance. Energy imports are a fundamental factor for many countries experiencing current account balance challenges. In this context, there have been an increasing number of studies on the relationship between energy consumption and current account deficit in recent years. 
Countries that are members of the Organization of the Black Sea Economic Cooperation (BSEC) were chosen as the sample because these countries are consequential in terms of economic potential, population, energy supply, and demand. A literature review determined that the relationship between energy consumption and current account deficit among BSEC countries has not yet been investigated. In this context, this study contributes to the literature in terms of the sample group and the applied econometric method.

In the study, the relationship between total energy consumption and current account balance is empirically examined in terms of BSEC member countries (Azerbaijan, Bulgaria, Armenia, Georgia, Moldova, Romania, Russia, Turkey, and Ukraine). Data reference the 1992-2014 (annual) period because of limitations in the availability of recent data on the countries included in the analysis. Current account balance was used as the dependent variable and total energy consumption as the independent variable. Gauss-10 and Eviews-12 package programs were used in the methodological implementation stages.

The econometric analysis initially examined the homogeneity and cross-section dependence of the panel, applying Swamy-S (1970) homogeneity and Pesaran (2004) crosssection dependence tests. Based on the results of these tests, a second-generation crosssectional augmented Dickey Fuller (CADF) panel unit root test, proposed by Pesaran (2007), was used. The CADF test results indicate that the variables have I (1) process. To determine the cointegration relationship between series, Westerlund (2007) panel cointegration test, which considers cross-section dependence, was used. Additionally, to examine the net effect of the independent variable on the dependent variable, the average group dynamic least squares estimator, which supports the heterogeneity and cross-sectional dependence assumptions developed by Pedroni (2001), was applied.

The findings of the homogeneity and cross-section dependence tests reveal that the dataset used in the study is suitable for second-generation panel methods. Within the scope of second-generation unit root, cointegration, and estimator results, energy consumption and current account deficit variables in BSEC countries appear to be cointegrated in the long run. Further, a one-unit change in energy consumption is shown to increase the current account deficit by 17.13 units.

The findings indicate that energy consumption (i.e., energy demand) exerts pressure on current account deficit in BSEC countries. This result indicates that BSEC countries cannot adequately meet their energy needs and resort to energy imports. Among the member states, particularly for Moldova, Turkey, Armenia, and Georgia, solving the problem of foreign dependency for energy is of critical importance in the context of current account deficit. Therefore, it is extremely important for BSEC countries to increase research on fossil and renewable energy sources to mitigate current account deficit challenges. 


\section{Giriş}

Dünya Bankası’nın verilerine göre, Dünya nüfusu 1960-2019 yılları arasında yaklaşık \%153 artarak 7.6 milyar seviyesine ulaşmıştır ${ }^{1}$. Hızlı nüfus artışı ve refah devleti anlayışı, toplumsal ihtiyaçların artışını tetiklemektedir. Diğer yandan Birleşmiş Milletler'e göre nüfusun yarısından fazlası kentlerde yaşamakta ve her yıl yaklaşık 75 milyon insan kırsal kesimden kentlere göç etmektedir. Özellikle kentleşme ile birlikte sosyal, ekonomik, kültürel alanlar başta olmak üzere birçok alanda yeni toplumsal talepler ortaya çıkmakta ve bu durum toplumsal ihtiyaçlara yönelik üretim kalıplarının değişmesine ve üretim miktarlarının artmasına neden olmaktadır (Kalkınma Bakanlığı, 2014, s. 25; Kalkınma Bakanlığı, 2018, s. 4).

Nüfus, kentleşme ve üretim rasyolarının bu denli hızlı arttığı günümüz dünyasında enerji talebi ve enerji tüketimi en önemli tartışma konularının başında gelmektedir. Enerji, özellikle sanayi devrimi sonrasında insanlık tarihinin en önemli ihtiyaçlarından biri olmuştur. Üretim aşamasında kullanılan önemli girdilerinden biri olması da enerjiye duyulan ihtiyacı her geçen gün artırmaktadır (Yanar \& Kerimoğlu, 2011, s. 191). Bu bağlamda, 1965 (43.248 TWh) - 2019 (162.194 TWh) yılları arasında Dünya'da birincil enerji tüketimi yaklaşık \%275 artmıştır. $^{2}$ Tüketilen enerjinin büyük bölümü fosil yakıtlardan oluşmaktadır. Örneğin 2015 yılında, fosil yakıt enerji tüketimi, toplam enerji tüketiminin yaklaşık \%80'ini temsil etmektedir. ${ }^{3}$ Bu veri, günümüzde yenilenebilir enerji kaynaklarına önem verilmesine karşın doğalgaz, petrol, kömür gibi fosil yakıt tüketiminin hala önemli seviyede olduğunu göstermektedir.

Dünyada enerji rezervlerinin dağılımı, ülkeler açısından doğal olarak dengeli değildir. Bu nedenle bazı ülkeler enerji kaynaklarına daha hızlı ve daha az masraf ile ulaşırken, bazı ülkeler daha zor ve maliyetli bir şekilde ulaşmaktadır. Ayrıca enerjiye ulaşım konusunda ülkelerdeki rezerv miktarı, ekonomik yapı, teknolojik imkanlar gibi birçok faktör rol oynamaktadır. Bu durum, enerji ihtiyacı olan ülkeleri, enerji üreten ve ihraç eden ülkelere bağımlı kılmaktadır. Nüfusa ve üretim koşullarına bağlı olarak artan enerji talebine karşılık enerjide dışa bağımlı olan ülkelerde, ödemeler dengesine dair sorunlar yaşanmaktadır. Enerji ithalatının cari açık açısından sorun arz etmesi, ekonomiyi kırılgan hale getirmektedir. Enerjiden kaynaklanan cari açık sorunun giderilmesi için ihracatın artırılması gerekmektedir. Ancak daha fazla ihracat yapabilmek için üretime ve dolaylı olarak daha fazla enerjiye ihtiyaç duyulmaktadır. Bu bağlamda, yerli enerji kaynakları ve yenilebilir enerji

\footnotetext{
${ }^{1}$ World Bank, https://data.worldbank.org/indicator/SP.POP.TOTL (18.05.2021).

${ }^{2}$ Our World in Data, https://ourworldindata.org/energy-production-consumption (18.05.2021).

${ }^{3}$ World Bank, https://data.worldbank.org/indicator/EG.USE.COMM.FO.ZS (18.05.2021).
} 
kaynaklarından daha fazla yararlanmaya yönelik politikaların geliştirilmesi çözüm olarak ifade edilebilmektedir (Demir, 2013, s. 3; Hepaktan, 2018, s. 143). Fakat teknolojik ve beşerî sermaye açısından yetersiz olan ülkelerde enerji rezervlerinin etkin bir şekilde değerlendirilmesi mümkün görünmemektedir. Dolayısıyla bu durumda olan ülkeler özellikle enerji arayışı ve üretimine yönelik hem kendi girişimcilerine hem de doğrudan yabancı yatırımlara yönelik gerekli teşvik tedbirlerini hayata geçirmelidir. Bu bağlamda tutarlı yönetişim yapısı, sektöre yönelik düzenleyici yapılar, uygulama kurallarının belirlenmesi, mülkiyet hakları ve güçlü hukuk düzeni gibi faktörler uygun bir yatırım ortamı için önem arz etmektedir Aslan, Gozbasi, Altinoz, \& Altuntas, 2021).

Çalışma, enerji tüketiminin cari açık üzerindeki etkisine odaklanmaktadır. Örneklem olarak Karadeniz Ekonomik İşbirliği Örgütü'ne (KEİ) üye olan ülkeler seçilmiştir. Bu örneklemin seçilme motivasyonu, bu ülkelerin enerji arzı ve talebi açısından önem arz etmesidir. 2018 yılında, KEİ ülkeleri Dünya'daki toplam enerji tüketiminin \%7.79'unu, toplam enerji üretiminin \%11.95 'ini ${ }^{5}$ temsil etmektedir. Diğer yandan KEİ ülkelerinin nüfus ve ekonomik potansiyelleri de önemli seviyededir. Örneğin, 2019 yılında KEİ ülkeleri Dünya'da toplam GSYH'nin (Satın alma gücü paritesine göre) \%6.13'ünü, toplam nüfusun $\%$ 4.13'ünü oluşturmaktadır ${ }^{6}$. Tarafımızca yapılan literatür araştırması sonucunda, enerji tüketimi ile cari açık arasındaki ilişkinin KEİ ülkeleri için daha önce araştırılmadığ görülmüştür. Bu bağlamda, çalışmanın örneklem grubu ve uygulanan ekonometrik yöntem açısından literatüre katkı sağlayacağı düşünülmektedir.

\section{Literatür Taraması}

Enerji tüketimi ile cari işlemlere dair literatür taraması Tablo 1'de gösterilmektedir. Çalışmalarda yoğunlukla eşbütünleşme ve nedensellik analizlerinin uygulandığ görülmektedir. İlgili analizlerin sonucunda genel olarak enerji tüketiminin cari işlemler dengesi ile etkileşim içinde olduğu ve cari açığı artırıcı yönde baskı oluştuğu bulguları yer almaktadır. Literatür genel olarak incelendiğinde, çalışmaların zaman serisi boyutunda olduğu görülmektedir. Bu çalışmada literatüre uygun olarak enerji tüketiminin cari açık üzerindeki etkisi incelenmektedir. Analizde uygulanan panel eşbütünleşme testi (Westerlund, 2007) ve panel tahminci yöntemi (Pedroni, 2001) literatürdeki diğer çalışmalardan ayrışmaktadır. Ayrıca analizde tercih edilen örneklem grubu ile zaman serisi ağırlıklı olan literatüre katkı sunulması amaçlanmaktadır.

\footnotetext{
${ }^{4}$ EIA, https://www.eia.gov/international/data/world (20.05.2021). (Örneklemdeki 9 ülkenin verisi).

${ }^{5}$ EIA, https://www.eia.gov/international/data/world (20.05.2021). (Örneklemdeki 9 ülkenin verisi).

${ }^{6} \mathrm{IMF}$, https://www.imf.org/en/Publications/WEO/weo-database/2021/April (21.05.2021). (Örneklemdeki 9 ülkenin verisi)
} 
Tablo 1: Literatür Taramasına Dair Çalışmalar

\begin{tabular}{|c|c|c|c|c|}
\hline Yazar(lar) & $\begin{array}{l}\text { Örneklem/ } \\
\text { Dönem }\end{array}$ & Değişkenler & Yöntem & Sonuç \\
\hline $\begin{array}{l}\text { Yanar ve } \\
\text { Kerimoğlu } \\
(2011)\end{array}$ & $\begin{array}{c}\text { Türkiye } \\
(1975-2009)\end{array}$ & $\begin{array}{l}\text { Enerji Tüketimi, } \\
\text { Ekonomik } \\
\text { Büyüme ve Cari } \\
\text { Açık }\end{array}$ & $\begin{array}{c}\text { Johansen } \\
\text { Eşbütünleşme } \\
\text { Testi }\end{array}$ & $\begin{array}{l}\text { Cari açık ve enerji tüketiminin birlikte } \\
\text { hareket ettiği sonucuna ulaşılmıştır. Enerji } \\
\text { tüketimindeki artışın cari açığı arttırıcı etki } \\
\text { yapacağı sonucuna ulaşmışlardır. }\end{array}$ \\
\hline $\begin{array}{l}\text { Demir } \\
(2013)\end{array}$ & $\begin{array}{c}\text { Türkiye } \\
(1987-2012)\end{array}$ & $\begin{array}{l}\text { Sanayi Üretimi, } \\
\text { Cari Açık ve } \\
\text { Enerji İthalatı }\end{array}$ & $\begin{array}{l}\text { Granger } \\
\text { Nedensellik } \\
\text { Testi }\end{array}$ & $\begin{array}{l}\text { Sanayi üretim endeksi ve enerji ithalatından } \\
\text { cari açığa doğru tek yönlü nedensellik olduğu } \\
\text { sonucuna ulaşı1lmıştır. }\end{array}$ \\
\hline $\begin{array}{l}\text { Ener, Kilıç, } \\
\text { ve Arıca } \\
(2013)\end{array}$ & $\begin{array}{c}\text { Seçilmiş } 32 \\
\text { üst-orta gelirli } \\
\text { ülke } \\
(1980-2011)\end{array}$ & $\begin{array}{l}\text { Toplam Petrol } \\
\text { Tüketimi ile Cari } \\
\text { İşlemler Dengesi }\end{array}$ & $\begin{array}{c}\text { Panel } \\
\text { Regresyon } \\
\text { Analizi-Sabit } \\
\text { Etkiler Modeli }\end{array}$ & $\begin{array}{l}\text { Toplam petrol tüketiminin azalmasının } \\
\text { ülkelerin cari işlemler dengesini iyileştirdiği } \\
\text { sonucuna ulaşılmıştır. }\end{array}$ \\
\hline $\begin{array}{l}\text { Kesikoğlu } \\
\text { ve Y1ldırım } \\
(2014)\end{array}$ & $\begin{array}{l}11 \text { OECD } \\
\text { ülkesi } \\
(1980-2012)\end{array}$ & $\begin{array}{l}\text { Doğalgaz/Petrol } \\
\text { Tüketimi ve Cari } \\
\text { İşlemler Dengesi }\end{array}$ & $\begin{array}{l}\text { Granger } \\
\text { Nedensellik } \\
\text { Testi }\end{array}$ & $\begin{array}{c}\text { İsviçre dışındaki ülkelerde cari denge } \\
\text { ile Doğalgaz/Petrol Tüketimi arasında } \\
\text { nedensellik ilişkisi olmadığı sonucuna } \\
\text { ulaşılmıştır. }\end{array}$ \\
\hline $\begin{array}{l}\text { Uysal, } \\
\text { Yılmaz, ve } \\
\text { Taş (2015) }\end{array}$ & $\begin{array}{c}\text { Türkiye } \\
(1980-2012)\end{array}$ & $\begin{array}{c}\text { Ekonomik } \\
\text { Büyüme, Enerji } \\
\text { Tüketimi ve Cari } \\
\text { Açık }\end{array}$ & $\begin{array}{c}\text { Johansen } \\
\text { Eşbütünleşme } \\
\text { Testi }\end{array}$ & $\begin{array}{l}\text { Analiz sonucunda enerji tüketimi ve cari } \\
\text { açıı̆ın uzun dönemde birlikte hareket ettiği } \\
\text { sonucuna ulaşılmıştır. }\end{array}$ \\
\hline $\begin{array}{l}\text { Gokten ve } \\
\text { Karatepe } \\
\text { (2016) }\end{array}$ & $\begin{array}{c}\text { Türkiye } \\
(1950-2010)\end{array}$ & $\begin{array}{c}\text { İthalata } \\
\text { Dayalı Enerji } \\
\text { Kaynakları ve } \\
\text { Cari İşlemler } \\
\text { Dengesi }\end{array}$ & $\begin{array}{l}\text { Granger } \\
\text { Nedensellik } \\
\text { Testi }\end{array}$ & $\begin{array}{l}\text { İthalata dayalı enerji kaynaklarından cari } \\
\text { açı̆ğa kadar uzanan çift yönlü bir nedensellik } \\
\text { olduğunu ifade edilmektedir. }\end{array}$ \\
\hline $\begin{array}{l}\text { Hepaktan } \\
(2018)\end{array}$ & $\begin{array}{c}\text { Türkiye } \\
(1990-2017)\end{array}$ & $\begin{array}{l}\text { Enerji Tüketimi, } \\
\text { Ekonomik } \\
\text { Büyüme ve Cari } \\
\text { İşlemler Açı̆̆ı }\end{array}$ & $\begin{array}{l}\text { Gregory- } \\
\text { Hansen } \\
\text { Eşbütünleşme } \\
\text { Testi ve Toda- } \\
\text { Yamamoto } \\
\text { Nedensellik } \\
\text { Testi }\end{array}$ & $\begin{array}{l}\text { Eşbütünleşme analizine göre seriler arasında } \\
\text { uzun dönemde bir ilişki olmadığı sonucuna } \\
\text { ulaşılmış̧ır. Nedensellik analizine göre, } \\
\text { enerji tüketimi ve cari işlemler açığından, } \\
\text { ekonomik büyümeye doğru tek yönlü bir ilişki } \\
\text { olduğu görülmüştür. Ayrıca, enerji tüketimi } \\
\text { ile cari işlemler açı̆̆ı arasında çift yönlü bir } \\
\text { nedensellik ilişkisi olduğu saptanmıştır. }\end{array}$ \\
\hline $\begin{array}{l}\text { Gökçe ve } \\
\text { Demirtaş } \\
\text { (2018) }\end{array}$ & $\begin{array}{l}\text { Avrupa Birliği } \\
\text { Ülkeleri ve } \\
\text { Türkiye }\end{array}$ & $\begin{array}{l}\text { Cari Denge, } \\
\text { Yenilenebilir } \\
\text { Enerji Tüketimi, } \\
\text { Ekonomik } \\
\text { Büyüme, Reel } \\
\text { Efektif Döviz } \\
\text { Kuru, Tasarruf ve } \\
\text { Enerji İthalatı }\end{array}$ & $\begin{array}{c}\text { Panel } \\
\text { Regresyon } \\
\text { Analizi-FGLS } \\
\text { (Feasible } \\
\text { Generalized } \\
\text { Least Square) }\end{array}$ & $\begin{array}{l}\text { Yenilenebilir enerji tüketimindeki oransal } \\
\text { artış, cari dengeyi olumlu yönde etkilemekte } \\
\text { iken enerjide dışa bağımlılık olumsuz yönde } \\
\text { etki etmektedir. }\end{array}$ \\
\hline $\begin{array}{l}\text { Sarıtaş, } \\
\text { Genç, } \\
\text { ve Avcı } \\
(2018)\end{array}$ & $\begin{array}{c}\text { Türkiye } \\
(1971-2015)\end{array}$ & $\begin{array}{c}\text { Ekonomik } \\
\text { Büyüme, Enerji } \\
\text { Itthalatı ve Cari } \\
\text { Açık }\end{array}$ & $\begin{array}{l}\text { Granger } \\
\text { Nedensellik } \\
\text { Testi }\end{array}$ & $\begin{array}{l}\text { Enerji ithalatının cari açığın Granger nedeni } \\
\text { olduğu tespit edilmiştir. }\end{array}$ \\
\hline
\end{tabular}




\begin{tabular}{|c|c|c|c|c|}
\hline $\begin{array}{l}\text { Ayla ve } \\
\text { Karış } \\
\text { (2019) }\end{array}$ & $\begin{array}{c}\text { Türkiye } \\
\text { (1984-2015) }\end{array}$ & $\begin{array}{l}\text { Cari Açık ve } \\
\text { Enerji İthalatı }\end{array}$ & $\begin{array}{l}\text { ARDL Sinır } \\
\text { Testi ve Toda- } \\
\text { Yamamoto } \\
\text { Nedensellik } \\
\text { Testi }\end{array}$ & $\begin{array}{l}\text { ARDL sınır testi sonuçlarına göre değişkenler } \\
\text { arasında eşbütünleşme ilişkisinin söz konusu } \\
\text { olduğu görülmüştür. Toda-Yamamoto } \\
\text { nedensellik testi sonuçlarına göre ise } \\
\text { değişkenler arasında tek yönlü ilişki vardır. }\end{array}$ \\
\hline $\begin{array}{l}\text { Uçak } \\
(2019)\end{array}$ & $\begin{array}{c}\text { Kırılgan Beşli } \\
\text { (Brezilya, } \\
\text { Hindistan, } \\
\text { Endonezya, } \\
\text { G.Afrika } \\
\text { ve Türkiye) } \\
\text { (1990-2017) }\end{array}$ & $\begin{array}{l}\text { Cari denge, } \\
\text { Yenilenebilir } \\
\text { Enerji ve Enerji } \\
\quad \text { İthalatı }\end{array}$ & $\begin{array}{l}\text { VAR Modeli } \\
\text { ve ARDL Sınır } \\
\text { Testi }\end{array}$ & $\begin{array}{l}\text { Değişkenler eşbütünleşiktir. Enerji } \\
\text { ithalatındaki \%1'lik artış, cari dengede } \\
\text { \%- } 0.27 \text { 'lik bozulmaya neden olmaktadır. } \\
\text { Enerji ithalatından cari dengeye doğru tek } \\
\text { yönlü nedensellik bulunmaktadır. Kesit } \\
\text { bazında ise Hindistan'da kısa dönemde } \\
\text { enerji ithalatındaki \%1'lik artış, cari dengede } \\
\text { \%-0.39'luk bozulmaya neden olmakta iken } \\
\text { Brezilya'da yenilenebilir enerjide \%1'lik artış, } \\
\text { cari dengede \%0.23'lük iyileşme meydana } \\
\text { getirmektedir. }\end{array}$ \\
\hline $\begin{array}{l}\text { Samanc1 } \\
(2019)\end{array}$ & $\begin{array}{c}\text { OECD } \\
\text { Ülkeleri } \\
(1995-2016)\end{array}$ & $\begin{array}{c}\text { Cari İşlemler } \\
\text { Dengesi, Enerji } \\
\text { İthalatı, Büyüme, } \\
\text { Dış Ticaret } \\
\text { Dengesi ve } \\
\text { İhracat }\end{array}$ & $\begin{array}{c}\text { Johansen } \\
\text { Eşbütünleşme } \\
\text { Testi ve } \\
\text { Granger } \\
\text { Nedensellik } \\
\text { Testi }\end{array}$ & $\begin{array}{l}\text { Johansen Eşbütünleşme Testi'ne göre, seriler } \\
\text { arasında bir tane, maksimum öz değer testinde } \\
\text { ise iki tane eşbütünleşme ilişkisi tespit } \\
\text { edilmiştir. Ayrıca enerji ithalatı ve cari açık } \\
\text { arasında çift yönlü nedensellik vardır. }\end{array}$ \\
\hline $\begin{array}{l}\text { K1zildere } \\
(2020)\end{array}$ & $\begin{array}{c}\text { Türkiye } \\
\text { (1974-2015) }\end{array}$ & $\begin{array}{l}\text { Ekonomik } \\
\text { Büyümenin, Cari } \\
\text { Açık ve Enerji } \\
\text { Tüketimi }\end{array}$ & $\begin{array}{c}\text { Granger } \\
\text { Nedensellik } \\
\text { Testi }\end{array}$ & $\begin{array}{l}\text { Enerji tüketiminden cari açığa nedensellik } \\
\text { ilişkisi olduğu sonucuna ulaşmıştır. }\end{array}$ \\
\hline
\end{tabular}

\section{Veri Seti, Model ve Ekonometrik Metodoloji}

\subsection{Veri ve Model}

Çalışmada, Karadeniz Ekonomik İşbirliği Örgütü’ne üye olan ülkeler (Azerbaycan, Bulgaristan, Ermenistan, Gürcistan, Moldova, Romanya, Rusya, Türkiye ve Ukrayna) ${ }^{7}$ açısından toplam enerji tüketimi ile cari açık arasındaki ilişki ampirik olarak incelenmektedir. Veriler 1992-2014 (yıllık) dönemine aittir. Bu örneklemin ve dönemin seçilme nedeni, analizde yer alan ülkelere dair verilerin kısıtlı olmasıdır. Ampirik analizde cari açık bağımlı değişken, toplam enerji tüketimi ise bağımsız değişken olarak kullanılmaktadır. Yöntemlerin uygulanma aşamalarında Gauss-10 ve Eviews-12 paket programlarından yararlanılmıştır. Analizdeki kullanılan ampirik model Eşitlik 1'de gösterildiği gibidir:

$$
c a_{i t}=a_{i t}+\text { enerji } i_{i t}+\varepsilon_{i t}
$$

Burada $c a$, cari açığ 1 ve , enerji tüketimi değişkenlerini temsil etmektedir. Cari işlemler dengesi, net mal ve hizmet ihracat, net birincil gelir ve net ikincil gelirin toplamından elde

\footnotetext{
${ }^{7}$ KEİ ülkelerine üye ülkelerin sayısı 12 olmakla birlikte Arnavutluk, Sırbistan ve Yunanistan veri eksikliği nedeniyle örneklem dışında bırakılmıştır.
} 
edilmektedir ve veriler cari ABD doları cinsindendir. Toplam enerji tüketimi değişkeni ise yerli üretim, ithalat ve stok değişikliklerinden, ihracat ve uluslararası taşımacılık yapan gemilere ve uçaklara tedarik edilen yakıtların çıkarılması şeklinde hesaplanmaktadır.

\subsection{Ekonometrik Metodoloji}

Çalışmanın ekonometrik analiz bölümünde değişkenler arasındaki uzun dönemli ilişkinin incelenmesinde kullanılan eşbütünleşme analizinden yararlanılmaktadır. Bu noktada veri setini en iyi açıklayan eşbütünleşme testinin belirlenebilmesi için bazı varsayımların test edilmesi gerekmektedir. Bu bağlamda çalışmanın ekonometrik metodoloji bölümünde ilk olarak uygun eşbütünleşme testinin belirlenmesi için kullanılan varsayımsal testler açıklanacaktır. Daha sonra varsayımlar sonucu belirlenen uygun eşbütünleşme testine ve uzun dönem katsayı tahmininde kullanılan tahminciye ilişkin teorik çerçeve açıklanacaktır.

\subsubsection{Swamy-S Testi (1970)}

Veri setindeki homojenik yapının incelenmesinde kullanılmaktadır. $N>T$ olduğu durumlarda daha güçlü sonuçlar vermektedir. Eğim katsayılarına uygulanan Swamy istatistiği Eşitlik 2'de gösterildiği gibidir:

$$
\hat{S}=\sum_{i=1}^{N}\left(\hat{\beta}_{i}-\hat{\beta}_{W F E}\right)^{\prime} \frac{X_{i}^{\prime} M_{\tau} X_{i}}{\widehat{\sigma}_{i}^{2}}\left(\hat{\beta}_{i}-\hat{\beta}_{W F E}\right) \sim \chi_{k(N-1)}^{2}
$$

burada $M_{\tau}=I_{T}-\tau_{T}\left(\tau_{T}^{\prime} \tau_{T}\right)^{-1} \tau_{T}^{\prime}$ ' dir. $I_{T}$ birim matristir ve $\hat{\sigma}_{i}^{2}=\frac{\left(y_{i}-X_{i} \widehat{\beta}_{i}\right)^{\prime} M_{\tau}\left(y_{i}-X_{i} \widehat{\beta}_{i}\right)}{(T-k-1)}$, dir. $\hat{\beta}_{W F E}$, Eşitlik 2.1'de gösterildiği gibidir:

$$
\hat{\beta}_{W F E}=\left(\sum_{i=1}^{N} \frac{X_{i}^{\prime} M_{\tau} X_{i}}{\widehat{\sigma}_{i}^{2}}\right)^{-1} \sum_{i=1}^{N} \frac{X_{i}^{\prime} M_{\tau} y_{i}}{\widehat{\sigma}_{i}^{2}}
$$

Swamy $\mathrm{S}$ testinde sıfır hipotezi $H_{o}: \beta_{i}=\beta$ (Homojen) şeklinde, alternatif hipotez $H_{o}: \beta_{i} \neq \beta$ (Heterojen) şeklinde kurulmaktadır. Hesaplanan Swamy $\mathrm{S}$ istatistiği $>$ kritik değer ise sıfir hipotezi reddedilmektedir (Pesaran \& Yamagata, 2008, s. 54).

\subsubsection{Testi (2004)}

Panel verisinde kesitler arasında bağımlılığın var olup olmadığının araştırılmasında kullanılmaktadır. Pesaran (2004) tarafından geliştirilmiştir. $C D_{L M}$ testinde ilk olarak Eşitlik 3 'teki temel model tahmin edilir:

$$
y_{i t}=a_{i}+\beta^{\prime}{ }_{i} x_{i, t}+u_{i, t} \quad, i=1,2,3, \ldots, N, t=1,2,3, \ldots, T
$$

burada $i$ kesit boyutu ve $t$ zaman boyutunu ifade etmektedir. $a_{i}$ sabit terim, $x_{i, t}$ bağımsız değişken vektörü ve $\beta$ eğim katsayısıdır. Her bir için $u_{i, t} \sim I I D\left(0, \sigma_{\mathrm{iu}}^{2}\right)^{\prime}$ dir. Breusch ve Pagan (1980), Eşitlik 3'ten elde edilen hatalar arasında korelasyon ilişkisi olması durumunu ele alarak LM testini geliştirmiştir. Bu test nispeten küçük $\mathrm{N}$ ve yeterince büyük T'ler için daha etkin sonuçlar vermektedir. Daha sonra Pesaran (2004) $T$ ve $N$ sonsuza gidiyor iken daha 
etkin sonuçlar veren $C D_{L M}$ testi geliştirilmiştir. $C D_{L M}$ istatistiği Eşitlik 4 'te gösterildiği gibidir:

$$
C D_{L M}=\sqrt{\frac{1}{N(N-1)}} \sum_{i=j}^{N-1} \sum_{j=i+1}^{N}\left(T \hat{\rho}_{i j}^{2}-1\right) \sim N(0,1)
$$

$C D_{L M}$ istatistiği $N>T$ olduğu durumlarda boyut bozulmaları oluşması nedeniyle etkinliğini kaybedebilmektedir. Bu nedenle $T>N$ olduğu durumlar için daha etkindir

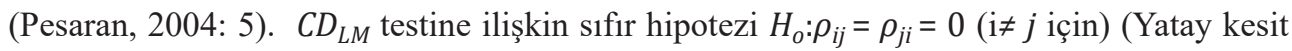
bağımlılık yoktur) şeklinde, alternatif hipotez $H_{A}: \rho_{i j}=\rho_{j i} \neq 0$ (i $\neq j$ için) (Yatay kesit bağımlılık vardır) şeklinde kurulmaktadır. $C D_{L M}$ istatistiğ $>$ kritik değer ise $H_{o}$ hipotezi reddedilmektedir.

\subsubsection{CADF (Cross-Sectional Augmented Dickey Fuller) Panel Birim Kök Testi (2007)}

Pesaran (2007) tarafından geliştirilmiştir. Yatay kesit bağımlılı̆̆ın varlığı ve veri setinin heterojen olduğu durumunda kullanılmaktadır. $N>T$ ve/veya $T>N$ farketmeksizin her iki durumda da kullanılabilmektedir. CADF testine ilişkin temel model Eşitlik 5'te gösterildiği gibidir (Pesaran, 2007, s. 268):

$$
\begin{aligned}
& y_{i t}=\left(1-\emptyset_{i}\right) \mu_{i}+\emptyset_{i} y_{i, t-1}+u_{i t} \\
& u_{i t}=\gamma_{i} f_{t}+\varepsilon_{i t}
\end{aligned}
$$

burada $f_{t}$ gözlenmeyen ortak etkileri (common effect) ve $\varepsilon_{i t}$, bireysel hatayı ifade etmektedir. Eşitlik 5 ve Eşitlik 5.1'in birleştirilmesiyle Eşitlik 6 elde edilebilmektedir:

$$
\Delta y_{i t}=a_{i}+\beta_{i} y_{i, t-1}+\gamma_{i} f_{t}+\varepsilon_{i t}
$$

burada $a_{i}=\left(1-\emptyset_{i}\right) \mu_{i}, \beta_{i}=-\left(1-\emptyset_{i}\right)$ ve $\Delta y_{i t}=y_{i t}-y_{i, t-1}$ şeklindedir. CADF testinde panel geneli için elde edilen istatistiğe CIPS (Crooss-Sectionally Im, Pesaran ve Shin) istatistiği olarak ifade edilmektedir ve Eşitlik 7'de gösterildiği gibi hesaplanmaktadır:

$$
C I P S=\frac{\sum_{\mathrm{i}=1}^{N} C A D F_{i}}{N}
$$

CADF testinde sıfır hipotezi $H_{o}: \beta_{i}=0$ (tüm $i$ 'ler için) (Birim kök vardır) şeklinde, alternatif hipotez $H_{A}: \beta_{i}<0\left(i=1,2,3, \ldots, N_{1} ; \beta_{i}=0, i=N_{1}+1, N_{1}+2, \ldots, N\right)$ (Birim kök yoktur) şeklinde kurulmaktadır. Hesaplanan CIPS istatistiği $>$ kritik değer ise sıfır hipotezi reddedilmektedir.

\subsubsection{Westerlund ECM (Error Correction Model) Panel EşbütünleşmeTesti (2007)}

Westerlund (2007) tarafindan önerilen bu test yatay kesit bağımlılığın varlığı, veri setinin heterojen olduğu ve serilerin birinci farklarında durağanlaştı̆̆ kullanılabilmektedir. Bu test hata düzeltme modeline (Error Correction Model (ECM)) 
dayanmaktadır. Bu nedenle Westerlund ECM panel eşbütünleşme testi olarak bilinmektedir. Burada başlangıç modeli Eşitlik 8'deki gibidir (Westerlund, 2007, s. 715):

$$
\Delta y_{i t}=\delta_{i}^{\prime} d_{t}+\alpha_{i} y_{i t-1}+\lambda_{i}^{\prime} x_{i t-1}+\sum_{j=1}^{p_{t}} \alpha_{i j} \Delta y_{i t-j}+\sum_{j=0}^{p_{t}} \gamma_{i j} \Delta x_{i t-j}+e_{i t}
$$

burada $d_{t}=(1, t)^{\prime}$ şeklindedir ve sabit ve trend değişkenlerini içerir. $\delta_{i}=\left(\delta_{1 i} \delta_{2 i}\right)^{\prime}$ ilişkili parametrelerin vektörüdür. $\lambda_{i}^{\prime}=-\alpha_{i} \beta_{i}$ olarak ifade edilmektedir. Westerlund (2007), farkl1 durumlar için dört farklı test istatistiği önermiştir. İlgili istatistikler şu şekildedir:

$$
\begin{aligned}
G_{\tau} & =\frac{1}{N} \sum_{i=1}^{N} \frac{\widehat{\alpha}_{i}}{\operatorname{SE}\left(\widehat{\alpha}_{i}\right)} \\
G_{\alpha} & =\frac{1}{N} \sum_{i=1}^{N} \frac{T \widehat{\alpha}_{i}}{\widehat{\alpha}_{i}(1)} \\
P_{\tau} & =\frac{\widehat{\alpha}}{S E(\widehat{\alpha})} \\
P_{\alpha} & =T \hat{\alpha}
\end{aligned}
$$

$P_{\tau}$ ve $P_{\alpha}$ panel ortalamalarına, $G_{\tau}$ ve $G_{\alpha}$ grup ortalamalarına dayanmaktadır. $\hat{\alpha}$ panel geneli için hata düzeltme katsayısı ve $S E(\hat{\alpha})$ hata düzeltme katsayısının standart hatasıdır. $S E\left(\hat{\alpha}_{i}\right)$, $\hat{\alpha}_{i}{ }^{\prime}$ nin standart hatasıdır.

Westerlund (2007) ECM panel eşbütünleşme testinde sıfır hipotezi $H_{o}: \alpha_{i}=0$ (Eşbütünleşme ilişkisi yoktur) şeklinde, alternatif hipotez $H_{A}: \alpha_{i}=\alpha<0$, (Eşbütünleşme ilişkisi vardır) şeklinde kurulmaktadır. Hesaplanan test istatistiğ $>$ kritik değer ise $H_{o}$ hipotezi reddedilmektedir.

\subsubsection{DOLSMG Panel Eşbütünleşme Tahmincisi (2001)}

Eşbütünleşme analizinde eşbütünleşik ilişkinin tespit edilmesi durumunda ilişkinin miktarını ve yönünü belirlemek için uzun dönem katsayı tahmini yapılabilmektedir. $\mathrm{Bu}$ noktada, bu çalışmada, Pedroni (2001) tarafından geliştirilen, yatay kesit bağımlılığ alan ve heterojen bir tahminci olan ortalama grup dinamik en küçük kareler (DOLSMG) tahmincisi kullanılmaktadır. Burada başlangıç noktası Eşitlik 13'te gösterilen panel eşbütünleşme modelidir (Pedroni, 2001, s. 728):

$$
Y_{i t}=\mu_{i}+\beta_{i} X_{i t}+u_{i t}
$$

Eşitlik 13'te verilen modele her bir kesit için öncül değerler ve gecikmeler eklenerek dinamik en küçük kareler (DOLS) yöntemi ile tahmin edilmektedir. Sonrasında her kesit için hesaplanan değerler Pesaran ve Smith MG yaklaşımı ile tüm panel değerini elde etmek için Eşitlik 14’te gösterildiği gibi birleştirilmektedir:

$$
\hat{\beta}_{\text {DOLSMG }}=N^{-1}\left[\sum_{i=1}^{N}\left(\sum_{t=1}^{T}\left(Z_{i t} Z_{i t}^{\prime}\right)\right)^{-1}\right]\left(\sum_{t=1}^{T}\left(Z_{i t} \bar{Y}_{i t}\right)\right)
$$


burada $Z_{i t}=\left(X_{i t}, \bar{X}_{i}, \Delta X_{i t-k}, \ldots, \Delta X_{i t+k}\right)$ açıklayıcı değişkenler vektördür. $\bar{Y}_{i t}=\Delta Y_{i t}-\bar{Y}_{i}$ 'şeklinde hesaplanmaktadır. Tahmin edilen katsayılara ilişkin t istatistiği ise $t_{\widehat{\beta}, D O L S M G}=N^{-1} \sum_{i=1}^{T} t_{\widehat{\beta}, D O L S, i}$ şeklinde hesaplanmaktadır. Burada $t_{\widehat{\beta}, D O L S, i}=\left(\hat{\beta}_{D O L S, i}-\beta\right)\left(\sigma_{i}^{-2} \sum_{t=1}^{T}\left(X_{i t}-\bar{X}_{i}\right)^{2}\right)^{1 / 2}$ dir.

\section{Ampirik Analiz}

Ekonometrik yöntemlere karar verilmesi aşamasında öncelikle homojenlik ve yatay kesit bağımlılı̆̆ı testlerinin yapılması gerekmektedir. Ardından varsayımlar analiz edilerek uygulanacak birinci veya ikinci nesil panel yöntemlerine karar verilecektir. Çalışmada, homojenlik Swamy (1970) ve yatay kesit bağımlılığı Pesaran (2004) testleri ile incelenmektedir. Tablo 2 ve 3 'teki bulgular, değişkenlerin ve panelin heterojen olduğunu ve yatay kesit bağımlılığı içerdiğini ortaya koymaktadır.

Tablo 2: Swamy-S (1970) Homojenlik Testi Sonuçları

\begin{tabular}{|c|c|c|}
\hline & \multicolumn{2}{|c|}{ Delta_tilde } \\
\hline enerji & \multicolumn{2}{|l|}{$3254.74 * * *$} \\
\hline $\mathrm{ca}$ & \multicolumn{2}{|l|}{$236.12 * * *$} \\
\hline Model & \multicolumn{2}{|l|}{$275.71 * * *$} \\
\hline \multicolumn{3}{|c|}{ Not: $* * *, * *$, ve $*$ sırasıyla $\% 1, \% 5$ ve $\% 10$ düzeyindeki anlamlıllğı ifade etmektedir. } \\
\hline \multicolumn{3}{|c|}{ Tablo 3: Pesaran (2004) Yatay Kesit Bağımlılık Testi } \\
\hline Variable & Sabitli & Sabitli ve Trendli \\
\hline enerji & $71.459 * * *$ & $57.919 * *$ \\
\hline $\mathrm{ca}$ & $77.937 * * *$ & $74.939 * * *$ \\
\hline Model & $93.095 * * *$ & \\
\hline
\end{tabular}

Panelin yatay kesit bağımlılı̆̆ içermesi, ikinci nesil panel testlere yönlendirmektedir. Tablo 4'te, Pesaran (2007) tarafindan geliştirilen ikinci nesil panel birim kök testi sonuçları gösterilmektedir. Bulgulara göre, panel açısından sabitli ve sabitli-trend model için seviyede birim kök içermekte iken birinci farkı alındığında durağanlaşmaktadır. 
Tablo 4: CADF Panel Birim Kök Test Sonuçları

\begin{tabular}{|c|c|c|c|c|}
\hline Sabitli & Seviye & & & \\
\hline & & $\mathrm{ca}$ & & enerji \\
\hline \multirow[t]{3}{*}{ Panel (CIPS) } & -1.725 & & -2.137 & \\
\hline & Birinci $F$ & & & \\
\hline & & $c a$ & & enerji \\
\hline Panel (CIPS) & $-3.308 *$ & & $-3.195^{*}$ & \\
\hline \multirow[t]{2}{*}{ Sabitli ve trendli } & Seviye & & & \\
\hline & & $c a$ & & enerji \\
\hline \multirow[t]{3}{*}{ Panel (CIPS) } & -2.382 & & -2.466 & \\
\hline & Birinci f & & & \\
\hline & & $c a$ & & enerji \\
\hline Panel (CIPS) & $-3.314 *$ & & $-3.404 * *$ & \\
\hline
\end{tabular}

Not: ***: \%1'deki anlamlılı̆̆ı, **: \%5'teki anlamlılığı, *: \%10'daki anlamlılığ ifade etmektedir. CADF testine ilişkin kritik değerler sabitli model için; - 4.11 (\%1), -3.36 (\%5), -2.97 (\%10), sabitli ve trendli model için; $-4.67(\% 1),-3.87(\% 5),-3.49$ (\%10)'dur. Yıllık veri olması nedeniyle maksimum gecikme uzunluğu 2 olarak belirlenmiştir.

Birim kök testinin bulguları kapsamında enerji tüketimi ile cari açık arasındaki uzun dönemli ilişkinin tespit edilmesine yönelik olarak Westerlund (2007) tarafından geliştirilen ikinci nesil eşbütünleşme testi uygulanmaktadır. Tablo 5 'te yer alan test sonucuna göre, $\% 10$ anlamlılık düzeyinde "eşbütünleşme yoktur" hipotezi reddedilmekte ve enerji tüketimi ile cari açık arasında uzun dönemli ilişki olduğu saptanmaktadır.

Tablo 5: Westerlund (2007) Panel Eşbütünleşme Test Sonuçları

\begin{tabular}{lcc}
\hline & Test İstatistiği $\left(\boldsymbol{g}_{\boldsymbol{\tau}}\right)$ & Bootstrap Olasılık Değeri \\
\hline ca_2 \& enerji & $-2.894(1)^{*}$ & 0.095 \\
\hline $\begin{array}{l}\text { Not: *** } * * \text { ve * sembolleri sırasılyla } \% 1, \% 5 \text { ve } \% 10 \text { düzeyinde anlamlılık düzeylerini ifade etmektedir. } \\
\text { Gecikme uzunluğu yıllık veri olması nedeniyle } 2 \text { olarak belirlenmiştir. Tabloda sabitli modele ilişkin } \\
\text { sonuçlar listelenmiştir. }\end{array}$
\end{tabular}

İki değişken arasında eşbütünleşme ilişkisinin tespit edilmesinin ardından bağımsız değişkenin bağımlı değişken üzerindeki net etkisinin incelenebilmesi açısından panel tahminci yöntemleri uygulanmaktadır. Bu kapsamda Pedroni (2001) tarafindan geliştirilen heterojenlik ve yatay kesit bağımlılığı varsayımlarını destekleyen DOLSMG tahmincisi uygulanmaktadır. Tahminci sonucuna göre, enerji tüketimindeki bir birimlik değişim cari açığı 17.13 birim artırmaktadır.

Tablo 6: DOLSMG Panel Eşbütünleşme Katsayı Tahminci Sonuçları

\begin{tabular}{lcc}
\hline \multicolumn{1}{c}{ beta } & t-istatistiği \\
\hline Panel & $17.13 * * *$ & -4.379 \\
\hline $\begin{array}{l}\text { Not: } * * *, * * \text { ve } * \text { sembolleri surasılyla } \% 1, \% 5 \text { ve } \% 10 \text { düzeyinde anlamlılık düzeylerini ifade etmektedir. } \\
\text { Gecikme uzunluğu yıllık veri olması nedeniyle } 2 \text { olarak belirlenmiştir. }\end{array}$
\end{tabular}




\section{Sonuç}

Çalışmada enerji tüketimi değişkeninin cari açık üzerindeki etkisi Karadeniz Ekonomik İşbirliği Örgütü'ne üye ülkeler açısından incelenmektedir. Yıllık olan veriler 1992-2014 dönemini kapsamaktadır. Homojenlik ve yatay kesit bağımlılığı testlerine dair bulgular, çalışmada kullanılan veri setinin ikinci nesil panel yöntemleri açısından uygun olduğunu ortaya koymaktadır. İkinci nesil birim kök, eşbütünleşme ve tahminci sonuçları kapsamında, KEİ ülkelerinde incelenen dönemde enerji tüketimi ile cari açık değişkenleri uzun dönemde eşbütünleşik hareket etmektedir. Ayrıca enerji tüketimindeki bir birimlik değişism, cari açığı 17.13 birim artırmaktadır. Analizden elde edilen bulgular, Yanar ve Kerimoğlu (2011), Uysal, Yılmaz ve Taş (2015) ve Ayla ve Karış (2019) çalışmalarındaki sonuçları destekler niteliktedir.

Bulgular, KEİ ülkelerinde enerji tüketimi yani enerji talebinin cari açık üzerinde baskı oluşturduğuna işaret etmektedir. Bu sonuç, KEİ ülkelerinin kendi enerji ihtiyaçlarını yeterince karşılayamadıklarını ve enerji ithalatına başvurduklarını göstermektedir. KEİ ülkeleri içerisinde enerji arzı ve ihracatı açısından Rusya ve Azerbaycan gibi çok önemli iki ülke bulunmasına karşın diğer üye ülkelerin enerji açısından dışa bağımlı oldukları görülmektedir. Örneğin 2014 yılında, kullanılan toplam enerji içerisinde enerji ithalatı oranları bazı KEİ üyesi ülkeleri için şu şekildedir: Moldova \%90.01, Türkiye \%74.20, Ermenistan \%71.34, Gürcistan 68.75, Bulgaristan \%36.55, Ukrayna \%27.20 ve Romanya $\% 16.77^{8}$. Üye ülkeler arasında özellikle Moldova, Türkiye, Ermenistan ve Gürcistan’ın enerji konusunda dışa bağımlılık sorununu çözmesi, cari açık sorunsalı açısından kritik önem taşımaktadır. Cari açık oranının yüksek olması döviz kuru, enflasyon, işsizlik, faiz oranı, gelir dağılımı gibi çeşitli göstergeleri olumsuz yönde etkileyebilmektedir. Dolayısıyla KEİ ülkelerinin kendi coğrafyalarındaki enerji kaynaklarına dair arayışların artması ve yenilebilir enerji kaynaklarına yönelmesi, enerji ithalatının minimize edilmesine fayda sağlayacaktır. Yenilenebilir enerji tüketimi her geçen gün artmaktadır. Analizde incelenen ülkelerde yenilenebilir enerjinin toplam enerji tüketimi içindeki payı 1990 yılında ortalama \%5.65 iken, 2015 yılında bu oran \%13.68 seviyesine yükselmiştir 9.

Sonuç olarak, KEİ ülkelerinin bir yandan fosil enerji kaynağı arayışlarını sürdürmesi, diğer yandan doğal kaynaklar temelinde yenilenebilir enerji tüketimine dair payın artırılması yönünde politikalar geliştirmelidir.

\footnotetext{
${ }^{8}$ World Bank, https://data.worldbank.org/indicator/EG.IMP.CONS.ZS?end=2015\&start=2014\&view=chart (21.05.2021).

${ }_{9}^{9}$ World Bank, https://data.worldbank.org/indicator/EG.FEC.RNEW.ZS?end=2015\&start=2015\&view=chart (21.05.2021).
} 
Hakem Değerlendirmesi: Dış bağımsız.

Çıkar Çatışması: Yazarlar çıkar çatışması bildirmemiştir.

Yazar Katkıları: Çalışma Konsepti/Tasarım- A.U., E.K.; Veri Toplama- Ş.P.; Veri Analizi/Yorumlama- E.K., E.Y.; Yazı TaslağıE.K., E.Y.; İçeriğin Eleştirel İncelemesi- A.U., Ş.P., E.K., E.Y.; Son Onay ve Sorumluluk- E.K., E.Y., A.U., Ş.P.; Malzeme ve Teknik Destek- A.U., Ş.P.; Süpervizyon- E.K., E.Y.

Finansal Destek: Yazarlar bu çalışma için finansal destek almadığını beyan etmiştir.

Peer-review: Externally peer-reviewed.

Author Contributions: Conception/Design of Study- A.U., E.K.; Data Acquisition- Ş.P.; Data Analysis/Interpretation- E.K., E.Y.; Drafting Manuscript- E.K., E.Y.; Critical Revision of Manuscript- A.U., Ş.P., E.K., E.Y.; Final Approval and Accountability- E.K., E.Y., A.U., Ş.P.; Material and Technical Support- A.U., Ş.P.; Supervision- E.K., E.Y.

Conflict of Interest: The authors have no conflict of interest to declare.

Grant Support: The authors declared that this study has received no financial support.

\section{Kaynakça/References}

Aslan, A., Gozbasi, O., Altinoz, B., \& Altuntas, M. (2021). Impact of financial development and economic growth on energy consumption: A panel vector autoregressive analysis for the comparison of G7 and Top 10 emerging market economies.

Ayla, D., \& Karış, Ç. (2019). Türkiye'de enerji ithalatı ve cari açık üzerine bir değerlendirme. Journal of Social Sciences/Sosyal Bilimler Dergisi, 32.

Breusch, T. S. \& Pagan, A. R. (1980). The Lagrange multiplier test and its applications to model specification in econometrics. The review of economic studies, 47(1), 239-253.

Demir, M. (2013). Enerji ithalati cari açik ilişkisi, VAR analizi ile Türkiye üzerine bir inceleme. Akademik Araştırmalar ve Çalışmalar Dergisi (AKAD), 5(9), 2-27.

EIA, https://www.eia.gov/international/data/world, Erişim Tarihi: 20.05.2021.

Ener, M., Kılıç, C., \& Arıca, F. (2013). The effect of total petroleum consumption on current account balance: An application for upper-middle countries. International Journal of Economy, Management and Social Sciences, 2(12), 996-1001.

Gokten, S., \& Karatepe, S. (2016). Electricity consumption and economic growth: A causality analysis for Turkey in the frame of import-based energy consumption and current account deficit. Energy Sources, Part B: Economics, Planning, and Policy, 11(4), 385-389.

Gökçe, C., \& Demirtaş, G. (2018). Cari denge açısından yenilenebilir enerjinin rolü: Avrupa Birliği ülkeleri ve Türkiye için panel veri analizi. Yönetim ve Ekonomi: Celal Bayar Üniversitesi İktisadi ve İdari Bilimler Fakültesi Dergisi, 25(3), 641-654.

Hepaktan, C. E. (2018). Türkiye'de enerji tüketimi, ekonomik büyüme ve cari işlemler açığı ilişkisinin yapısal kırılmalar altında ekonometrik analizi. Celal Bayar Üniversitesi Sosyal Bilimler Dergisi, 16(04), 141-160.

IMF, https://www.imf.org/en/Publications/WEO/weo-database/2021/April, Erişim Tarihi: 21.05.2021.

Kalkınma Bakanlığı (2014). Enerji Güvenliği ve Verimliliği. Özel İhtisas Komisyonu Raporu, Onuncu Kalkınma Planı 2014-2018, Ankara.

Kalkınma Bakanlığı (2018). Enerji Arz Güvenliği ve Verimliliği. Özel İhtisas Komisyonu Raporu, On Birinci Kalkınma Planı 2019-2023, Ankara.

Kesikoğlu, F., \& Yıldırım, E. (2014). The causal effect of shifting oil to natural gas consumption on current account balance and economic growth in 11 OECD countries: Evidence from bootstrap-corrected panel causality test. Procedia-Social and Behavioral Sciences, 143, 1064-1069. 
Kızıldere, C. (2020). Türkiye'de cari açık sorununun enerji tüketimi ve ekonomik büyüme açısından değerlendirilmesi: Ampirik bir analiz. Business \& Management Studies: An International Journal, 8(2), 21212139.

Our World in Data, https://ourworldindata.org/energy-production-consumption, Erişim Tarihi: 18.05.2021.

Pedroni, P. (2001). Purchasing power parity tests in cointegrated panels. Review of Economics and statistics, 83(4), 727-731.

Pesaran, H, M. (2004). General diagnostic tests for cross section dependence in panels. Working Paper, No: 0435, University of Cambridge.

Pesaran, M. H. (2007). A Simple panel unit root test in the presence of cross-section dependence. Journal of applied econometrics, 22(2), 265-312.

Pesaran, M. H., \& Yamagata, T. (2008). Testing slope homogeneity in large panels. Journal of econometrics, 142(1), 50-93.

Samancı, B., (2019). Enerji İthalatının Cari Denge Üzerine Etkileri: OECD Ülkeleri Üzerine Ampirik Bir Analiz. (Yayımlanmamış yüksek lisans tezi). Karamanoğlu Mehmetbey Üniversitesi, Sosyal Bilimler Enstitüsü, Karaman.

Sarıtaş, H., Genç, A., \& Avcı, T. (2018). Türkiye'de enerji ithalatı, cari açık ve büyüme ilişkisi: VAR ve Granger nedensellik analizi. Ekonomik ve Sosyal Araştırmalar Dergisi, 14(2), 181-200.

Swamy, P. A. (1970). Efficient inference in a random coefficient regression model. Econometrica: Journal of the Econometric Society, 311-323.

Uçak, S. (2019). Cari denge-yenilenebilir enerji: Kırılgan beşli örneği. Yönetim ve Ekonomi Araştırmaları Dergisi, 17(3), 106-122.

Uysal, D., Yılmaz, K., \& Taş, T. (2015). Enerji ithalatı ve cari açık ilişkisi: Türkiye Örneği. Anemon Muş Alparslan Üniversitesi Sosyal Bilimler Dergisi, 3(1), 63-78.

Westerlund, J. (2007). Testing for error correction in panel data. Oxford Bulletin of Economics and statistics, 69(6), 709-748.

World Bank, https://data.worldbank.org/indicator/EG.FEC.RNEW.ZS?end=2015\&start=2015\&view=chart, Erişim Tarihi: 21.05.2021.

World Bank, https://data.worldbank.org/indicator/EG.IMP.CONS.ZS?end=2015\&start=2014\&view=chart, Erişim Tarihi: 21.05.2021.

World Bank, https://data.worldbank.org/indicator/EG.USE.COMM.FO.ZS , Erişim Tarihi: 18.05.2021.

World Bank, https://data.worldbank.org/indicator/SP.POP.TOTL, Erişim Tarihi: 18.05.2021.

Yanar, R., \& Kerimoğlu, G. (2011). Türkiye'de enerji tüketimi, ekonomik büyüme ve cari açık ilişkisi. Ekonomi Bilimleri Dergisi, 3(2), 191-201. 
